\title{
Analysis on the Path of Combination of Scientific Basic Medicine and Clinical Medicine in Vocational Colleges
}

Jinniang Nan

Jiangxi Health Vocational College, Nanchang 330052, Jiangxi Province, China

\begin{abstract}
In the current science teaching in vocational colleges, basic medicine and clinical medicine play an important role in cultivating students' career development. They are the key courses to strengthen students' comprehensive ability and improve students' application skills. However, in the current internal medicine teaching, there is a problem that the combination of the two teaching is not close, which leads to some difficulties in learning. Under this background, this paper analyzes the current situation of science teaching in vocational colleges, and then puts forward the effective path of the combination of basic medicine and clinical medicine teaching.
\end{abstract}

Key words: Medicine; Basic medicine; Clinical medicine; Combination

Publication date: December, 2020

Publication online: 31 December, 2020

"Corresponding author: Jinniang Nan, 3161983526

(a)qq.com

In the teaching of internal medicine, the theoretical basis is the foundation of students' learning. Therefore, it is necessary to fully master the basic medical courses, and understand the pathology and symptoms of various diseases; Clinical medicine is the learning process of students from theory to practice, the only way for students to grow their professional ability, and also the core of students' employment development. Therefore, in the teaching reform of internal medicine, we need to comprehensively promote the integration of basic medicine and clinical medicine, and provide diversified support for the growth of students.

\section{Analysis on the current situation of science teaching in Vocational Colleges}

\subsection{Analysis of students' ability}

For the students in our school, there are two main problems. One is that the students' self-learning ability is generally poor. They can not maintain good self-control and enthusiasm, use their spare time to further improve their own foundation, lack the consciousness of active thinking and exploration, and lack of questioning and thinking operation in class, which leads to poor learning effect. On the one hand, students' understanding ability is poor, and teachers need to guide and analyze them more deeply in the process of learning; On the other hand, the poor comprehensive quality, including handson ability, team consciousness, cooperation ability, communication and coordination, is also the key factor affecting their learning efficiency.

\subsection{Analysis of medical examination}

In the current environment, the examination types of licensed doctors are constantly upgrading and changing. The main change is that the examination focuses on the ingenious combination of basic knowledge and clinical practice, which requires students to master the theoretical content explained in basic medicine, analyze according to medical theory, and have certain clinical practice experience, and discuss the problems in combination with practice. The existing problems and coping strategies. Therefore, in the teaching of internal medicine, it is necessary to take the examination of medical practitioners as the guidance. By promoting the combination of basic medicine and clinical medicine, 
it can not only meet the requirements of the current society for medical talents, but also help students better cope with the examination and reduce the difficulty of the examination.

\subsection{Analysis of teaching needs}

From the perspective of teachers' teaching, internal medicine is a subject with both theoretical and practical nature. Theory is the basic content and clinical practice is the practical means. In order to cultivate students with employability, we must strengthen the students' clinical experience and practical ability, and practical practice must rely on solid theoretical basis. Only by mastering anatomy, physiology, pathology and pharmacology can we cultivate students with employability. In order to have a deeper understanding in clinical practice and master the basis of its operation skills, we should have the basic knowledge of physical and mental health and other aspects. Therefore, from the perspective of the hierarchical and progressive relationship of teaching content, teachers need to integrate basic medicine and clinical medicine, so as to reduce the difficulty of students' learning.

\section{Analysis on the path of combination of basic medicine and clinical medicine}

\subsection{Promote the combination of curriculum, theory and clinical teaching}

In the process of internal medicine teaching, teachers can cut in the combination from the perspective of curriculum and implement the integrated teaching mode. First of all, in the theoretical teaching stage of basic medicine, teachers should pay attention to the analysis based on clinical cases, especially in basic courses such as physiology. Through the interposition and explanation of cases, we can not only set up discussion activities to deepen students' cognition of theoretical basis, but also effectively improve students' mastery of clinical medicine and have a certain ability to answer practical problems. Secondly, in the clinical practice teaching stage, teachers can guide students to find out the physiology, pathology and other textbooks during the internship. When learning the related diseases, they can combine the theoretical description in the textbook with the performance of the actual cases, so as to enable students to further establish clinical thinking and be able to deal with practical problems in a flexible way.

\subsection{Giving full play to teaching effect and apply-} ing multiple teaching methods

In the clinical practice teaching of internal medicine, teachers are generally required to have rich clinical experience and good scientific research ability. In the teaching process, students' theoretical knowledge and clinical ability can be taken into account, and the effective integration of basic medicine and clinical medicine can be realized through diversified teaching methods. First, teachers can use PBL teaching method, that is, teaching design around the problem center. First, teachers need to make full preparations before teaching, including the analysis of teaching content, the understanding of students' ability and the cognition of clinical diseases. Then, combined with the three, they take knowledge as the introduction way, and clinical cases as the explanation and analysis materials, and then set up problems that meet students' ability and teaching objectives; Second, teachers need to strengthen the teaching control ability and students' guiding ability. In the teaching process, students can be interested in the corresponding problems by organizing student activities or other ways, and then they can think and explore independently or in groups, so as to improve students' ability to analyze, think and solve problems. At the same time, it is also to cultivate students' clinical thinking and the combination of theory and practice. The important process of thinking.

Secondly, teachers can adopt the project teaching method, taking the diagnosis, analysis and treatment process of clinical patients as the basic idea of teaching. In the diagnosis link, students need to effectively combine clinical practice experience with theory, observe the symptoms of patients, and then analyze the pathology and etiology according to the theoretical basis; In the treatment process, students need to start from the perspective of pharmacology, contact the actual state of patients, and then put forward effective solutions. In this way, it can also promote the effective combination of basic medicine and clinical medicine.

Thirdly, teachers can also adopt case teaching mode. In the practice teaching of internal medicine, teachers should set up clinical cases for students in the first step, and carry out the explanation and discussion meeting. Students are required to analyze 
the typical symptoms in clinical cases in combination with their own basic medical knowledge, so as to strengthen the students' ability of theoretical application and thinking analysis, so as to lay the foundation for the follow-up clinical practice and scientific research development. In the second step, teachers can use clinical cases to set up teaching situations, such as hospital emergency in the middle of the night, patients with a variety of diseases, so as to specify the time and method of case presentation for students, and further improve students' clinical cognition and application ability of basic medicine by increasing the difficulty. In addition, teachers can also use different teaching methods, such as task driven, situation creation, etc., which can not only bring students different learning feelings, but also promote their integrated teaching through multiple methods.

\subsection{Developing practice teaching and training standard patients}

In the process of practice teaching, teachers can also carry out TSSP teaching by training standard patients. First of all, teachers should make a comprehensive arrangement and summary of typical clinical cases, and collect the most typical cases suitable for the teaching process, so as to set up standardized patients. Secondly, students are required to complete the work of medical history collection under the guidance of teachers according to the cases of standard patients. At the same time, according to the curriculum requirements of basic medicine, students are required to write standardized medical record forms and cooperate to complete auxiliary examinations. In this process, teachers can assess the clinical manifestations and basic clinical theories to guide students to master the ability of theoretical application. In addition, teachers should pay attention to the design of standard patients. Generally, teachers can choose to simulate by themselves. Through the communication with students, they can infiltrate the guidance to students, so that students can develop objective, fair, active and scientific clinical practice ability.

\subsection{Integrating information technology to promote the application of media teaching}

In addition, teachers also need to further use information technology to create an information- based teaching mode of internal medicine. On the one hand, we can use standardized teaching courseware, CD-ROM video materials and other information resources to carry out teaching, and present the teaching content in a more intuitive way, which can not only visualize the theoretical knowledge, but also make the clinical cases dynamic, so that students can participate in learning with more interest and achieve good learning effect. On the other hand, teachers themselves can also use photography, photography and other technologies to collect cases in the actual medical diagnosis and treatment work. On the basis of respecting the privacy of patients, teachers can use them as teaching materials, and present them in the classroom teaching process, or set them as situations, or show them as cases, or carry out inquiry activities, so that students can analyze them in more real cases and learn from them Deep integration of basic medicine and clinical medicine.

\section{Conclusion}

To sum up, in the current internal medicine teaching, from the perspective of students, medical practitioners examination and teaching needs, it can be found that the combination of basic medicine and clinical medicine is the inevitable direction of teachers' teaching reform. Therefore, teachers need to use the combination of curriculum, multiple means of teaching, standard patient teaching, media teaching and other means and measures to comprehensively promote basic medicine and clinical medicine In order to construct the integrated teaching system of theory and clinical medicine, the students' comprehensive ability can be better developed.

\section{References}

[1] Liu HX, Guan JM, Ma JW. Exploration and practice of integrating basic medical courses with cases in clinical medicine specialty of Higher Vocational Colleges [J]. Sichuan Journal of Physiological Sciences, 2020,42 (03): 339-342.

[2] Wu L. Discussion on the combination of basic medical teaching and clinical practice $[\mathrm{J}]$. New Campus (first ten days), 2018 (04): 108.

[3] Lin LR, Liu YW. The role of PBL combined with CBS teaching in basic medicine to clinical medicine learning $[\mathrm{J}]$. Gansu Medicine,2017,36(02):154-155. 